\title{
Potentiation of locomotor activity by d-amphetamine in infant Swiss-Webster mice
}

\author{
MICHAEL J. FORSTER and Z. MICHAEL NAGY \\ Bowling Green State University, Bowling Green, Ohio
}

\begin{abstract}
Swiss-Webster mice were tested for locomotor activity in either an electromagnetic field $(5,7$, or 9 days of age) or photocell shuttle $(9,11$, or 13 days of age) apparatus over a 4-h period following systematic injections of d-amphetamine or saline. While d-amphetamine reliably increased activity at all ages tested, the magnitude of the increase varied both as a function of age and apparatus, with younger mice showing a smaller increment than older mice in each apparatus and the electromagnetic field showing relatively greater increments than the photocell apparatus. In addition, amphetamine-induced hyperactivity for the age groups tested was always of longer duration than that reported for adult mice and rats, regardless of the type of apparatus. The present findings for mice are consistent with those that demonstrated that rats respond to amphetamine at early ages and also indicate that both species show similar age differences in the temporal effects of systematically administered amphetamine.
\end{abstract}

For altricial species, such as the mouse or rat, considerable maturational change in the biochemistry and morphology of the various neurotransmitter systems occurs between birth and adulthood (Lanier, Dunn, \& Van Hartesveldt, 1976). Studies of ontogenetic changes in the behavioral responses to drugs that affect these neurotransmitter systems suggest that some systems may reach functional maturity at different times with respect to certain behaviors. For the rat, it has been postulated that catecholamine (CA) systems function to modulate locomotor arousal much earlier in development than do cholinergic or serotonergic systems. Activity increases in response to the CA stimulant d-amphetamine are detectable in neonatal rat pups by 10 days of age (Campbell, Lytle, \& Fibiger, 1969; Lytle \& Meyer, 1978; Sobrian, Weltman, \& Pappas, 1975), as are activity decreases in response to drugs that deplete CAs (Campbell \& Mabry, 1973). In contrast, drugs thought to alter serotonergic (Mabry \& Campbell, 1974) or cholinergic (Campbell et al., 1969) neurotransmission do not elicit adult-like patterns of activity until the 15 th and 20th postnatal days, respectively.

The purpose of the present investigation was to assess the locomotor stimulant effects of d-amphetamine in the developing Swiss-Webster (S-W) mouse. Previous pharmacological studies of the $\mathrm{S}-\mathrm{W}$ mouse have indicated that serotonergic (Porada, 1975) and

This research was supported by a grant from the National Institute of Child Health and Human Development (HD-01945) to Z. Michael Nagy. Requests for reprints should be directed to Z. Michael Nagy, Department of Psychology, Bowling Green State University, Bowling Green, Ohio 43403. cholinergic (Ray \& Nagy, 1978) modulation of locomotor activity begin by 13 and 19 days of age, respectively. The detection of locomotor stimulant effects of amphetamine in mice prior to these ages would be consistent with existing data for the developing rat.

\section{EXPERIMENT 1}

In the first experiment, the effects of the CA stimulant, d-amphetamine, upon locomotor activity were examined in 9-, 11-, and 13-day-old mice. Because a pilot dose-response study had indicated that locomotor activity of 12-day-old mice was maximally sensitive to $4 \mathrm{mg} / \mathrm{kg}$ d-amphetamine, this dose was employed at all ages tested in the present studies.

\section{Method}

Animals. The animals were $96 \mathrm{~S}-\mathrm{W}$ albino mice (Mus musculus) born and reared in the Bowling Green State University Psychology Department mouse colony. The mice were housed in $30.4 \times 18 \times$ $12.8 \mathrm{~cm}$ polyethylene cages with wire-grid tops and wood chips on the cage floors. Mothers remained with the pups at all times except for testing sessions and were provided with nesting material and ad-lib food and water. The mouse colony room was on a normal 12-h light-dark cycle beginning at $0800 \mathrm{~h}$ and was maintained at $24^{\circ} \pm 1^{\circ} \mathrm{C}$. Pregnant females were checked for births daily at 0800 and $2000 \mathrm{~h}$, with the day following birth being designated as Postnatal Day 1. All litters used in the present studies were culled to nine pups each by Postnatal Day 2.

Apparatus. Mice were tested in clear acrylic cages measuring $19.4 \times 6.4 \times 9 \mathrm{~cm}$, with grid floors made from 1-mm-diameter stainless steel rods spaced $5.0 \mathrm{~mm}$ center-to-center and extending parallel to the length of the cage. Photocells were spaced $3.4 \mathrm{~cm}$ from each end of the cage, each opposite a red-filtered light source. One activity count was registered each time the mouse traversed the full $12.6-\mathrm{cm}$ distance between the photocells, break- 
ing alternate photocell beams. The activity cages were individually housed in sound-attenuated chambers, each equipped with a 6-W incandescent ceiling light for illumination and a ventilation fan that provided a 74-dB ambient noise level within the chamber. Total activity within 30-min intervals was recorded by printout counters and apparatus located outside the chambers.

Procedure. Separate groups of eight male and eight female mice were tested for locomotor activity over a 4-h period at 9,11 , or 13 days of age immediately following drug or saline injections. All mice received a 30-min pretest just prior to injections and were assigned to drug or saline groups such that preinjection activity was nearly equal for the two groups at each age. Drug groups received intraperitoneal (ip) injections of $4 \mathrm{mg} / \mathrm{kg}$ d-amphetamine (damphetamine sulfate; Smith, Kline, \& French), while saline groups received equivalent volumes of $0.9 \%$ saline immediately prior to testing. Only two like-sexed mice from any one litter were tested, one mouse being assigned to each drug condition. A single litter was represented at only one age.

\section{Results}

Drug, sex, and age were considered as factors in an analysis of variance on body weights of mice tested in Experiment 1 . That analysis indicated that body weight showed an overall increase with age $[F(2,84)$ $=37.3, \mathrm{p}<.0005$ ] but indicated no effects that would question the physical equivalence of mice assigned to drug and saline groups (all other Fs $<1.3$ ).

Figure 1 shows mean pre- and postinjection cage crossings as a function of age, 30 -min intervals, and drug group. As indicated in the figure, mean preinjection crossings of mice assigned to saline and amphetamine groups were roughly equivalent at each age. A three-way analysis of variance conducted on preinjection activity supported this observation, indicating no significant main effect of drug assignment or interaction of drug assignment with sex or age (all Fs < 1.0). A four-way analysis of variance with one repeated factor (30-min intervals) was conducted on postinjection activity. As can be clearly seen in Figure 1, the effect of amphetamine treatment varied markedly among the age groups. Amphetaminetreated mice made more cage crossings than control

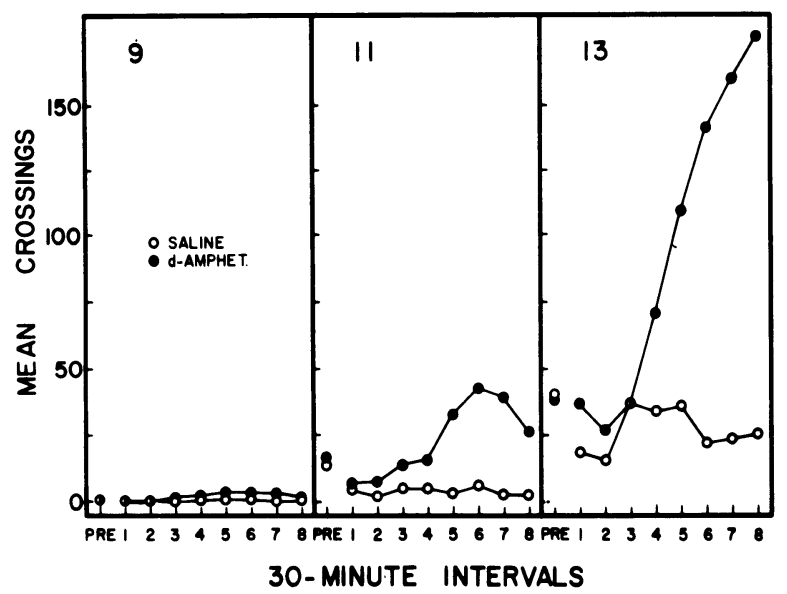

Figure 1. Mean numbers of cage crossings during pre- and postinjection activity tests as a function of age, drug group, and 30 min intervals. groups mainly at 11 and 13 days of age, with the greatest difference appearing at 13 days. The agerelated increase in amphetamine response resulted in a drug $\times$ age interaction $[F(2,84)=17.7, \mathrm{p}<.0005]$ in addition to main effects of drug $[F(1,84)=39.6$, $\mathrm{p}<.0005]$ and age $[\mathrm{F}(2,84)=59.5, \mathrm{p}<.0005]$.

Activity also varied as a function of intervals $[F(7,588)=16.8, p<.0005]$, and significant two-way interactions of intervals with age and drug (all Fs $<$ 9.4, all ps $<.0005$ ) and a drug $\times$ age $\times$ intervals interaction $[F(14,588)=9.2, p<.0005]$ reflected the changing temporal characteristics of activity after amphetamine with increasing age. Both 11- and 13day-olds showed activity increases beginning during the 2nd hour following amphetamine, but activity of the 11-day-old amphetamine group peaked and subsequently declined during the 3 rd and 4 th hours following treatments, while activity of the 13-day-old amphetamine group continued to increase for the remainder of the session. Additional findings were sex $X$ intervals $[F(7,588)=3.0, p<.0005]$ and $\operatorname{sex} x$ age $x$ intervals $[F(14,588)=2.1, \mathrm{p}<.01]$ interactions. These interactions were attributable to the higher activity of 11 - and 13-day-old females relative to that of males during the initial $15 \mathrm{~min}$ of testing and to other relatively small differences between the sexes over intervals that were inconsistent among the age groups.

Consistent with the pattern shown in Figure 1, planned individual comparisons (after Winer, 1971) conducted within the drug $\times$ age interaction indicated that amphetamine groups differed significantly from controls only at 11 and 13 days of age $[\mathrm{Fs}(1,84)>5.5$, ps $<.025]$, the difference at 9 days being nonsignificant $(F<1.0)$. However, $F_{\max }$ tests indicated that overall error variance increased significantly with each increase in age $\left[F_{\max }(2,32)>\right.$ 8.3, ps $<.01$ ], suggesting that significant drug effects at 9 days of age had perhaps been obscured by the relatively greater variability among 11- and 13-dayold groups. When the 9-day-old groups were analyzed separately from the 11- and 13-day-old groups, a significant difference between 9-day-old saline and amphetamine groups was obtained $[F(1,28)=22.4$, $\mathrm{p}<.0005$ ], even though the potentiation of crossings by amphetamine at this age was quite small relative to those obtained at 11 and 13 days of age. Although barely visible in Figure 1, the temporal characteristics of amphetamine at this age were similar to those observed at 11 days, with the peak response occurring during the 3rd hour postinjection. This temporal pattern resulted in a significant main effect of intervals $[F(7,196)=5.5, p<.0005]$ and a drug $x$ intervals interaction $[F(7,196)=4.4, p<.0005]$. A sex $x$ drug interaction $[F(1,28)=5.0, p .<.05]$ was also obtained, due to the relatively greater overall response to amphetamine by females than by males. Separate analyses of variance conducted at 11 and 13 
days confirmed previous decisions regarding drug group differences at those ages.

\section{EXPERIMENT 2}

While the age-related increase in locomotor response to amphetamine in Experiment 1 could be interpreted as reflecting maturation of those neural systems mediating the locomotor stimulant effects of amphetamine, the data did not rule out other possibilities. One possibility was that 9-day-old mice were less capable of activity increases than older mice because they lacked the requisite locomotor abilities. Another possibility was that amphetamine-elicited activity of 9-day-olds did not typically result in photocell crossings. In either case, the results of Experiment 1 suggested that a more sensitive activity measure would be required to provide a powerful test for the presence of locomotor stimulant effects of amphetamine in younger mice. Accordingly, an apparatus that required less overall movement for recording of activity was employed in the present study. This apparatus, which records activity by means of an electromagnetic field, was designed such that it could measure movement within the photocell cage while photocell crossings were recorded concurrently. In the present experiment, the amphetamine response of 9-day-old mice tested in a photocell cage was recorded by both apparatuses in order to compare the two activity measures. It was expected that at 9 days of age, amphetamine effects would be most apparent in terms of the electromagnetic field activity measure, especially if amphetamine-induced activity of 9-day-olds had a more restricted topography than that of older age groups.

\section{Method}

Animals. Animals were $32 \mathrm{~S}-\mathrm{W}$ mice born and reared under the conditions outlined in Experiment 1.

Apparatus. A photocell cage was placed upon the sensing surface of a Stoelting electronic activity monitor (EAM, Model 31404). The EAM recorded gross movement independently of photocells that recorded numbers of cage crossings. The EAM power supply was set at . $8 \mathrm{~mA}$, and the normal threshold reset time was selected. The photocell cage, photocells, and red-filtered light sources were the same as those used in Experiment 1, with the exception that a solid, clear acrylic cage bottom was used in place of the grid floor. (The stainless steel grid floor could not be used as it interfered with the recording of activity by the EAM.) The flour of the photocell cage was $1.6 \mathrm{~cm}$ above the sensor of the EAM. Testing took place within a sound-attenuated chamber equipped with a 6-W incandescent ceiling light for illumination and a ventilation fan that provided a 74-dB ambient noise level within the chamber. Cage crossings and EAM activity within 30-min intervals were recorded by separate printout counters and apparatus located outside the chamber.

Procedure. Separate groups of 9-day-old mice (8 males and 8 females each) were tested for a 4-h session immediately following either saline or $4-\mathrm{mg} / \mathrm{kg}$ d-amphetamine injections. The mice were assigned to drug groups immediately following a 30-min preinjection activity session such that preinjection activity was nearly equal for drug and saline groups. Only two like-sexed mice from any one litter were tested, one mouse being assigned to each drug condition.

\section{Results and Discussion}

Separate two-way analyses of variance conducted on preinjection activity for each measure (cage crossings and EAM activity) failed to indicate significant differences between drug and saline groups for either activity measure (all Fs $<1.0$ ). A separate three-way analysis of variance was conducted on postinjection activity for each dependent measure, with drug, sex, and 30 -min intervals as factors. Figure 2 shows preand postinjection EAM activity (left scale) and cage crossings (right scale) as a function of drug and 30min intervals. Significant main effects of amphetamine treatment were obtained in terms of both EAM activity $[F(1,28)=28.8, p<.0005]$ and photocell crossings $[\mathrm{F}(1,28)=10.5, \mathrm{p}<.005]$, although a comparatively greater effect with the EAM measure can be seen in Figure 2 by comparing the two measures in terms of initial activity relative to peak activity following amphetamine injection. Photocell crossings showed roughly an eight-fold increase from Interval 1 to Interval 6, while the increase in EAM activity between Intervals 1 and 5 was roughly 19-fold. Both analyses also indicated significant main effects of 30-min intervals (Fs $>4.7$, ps $<.0005$ ) and drug $X$ intervals interactions (Fs $>4.6$, ps $<.0005$ ), and, as Figure 2 indicates, drug group differences in EAM activity activity and photocell crossings had similar temporal characteristics.

While the appearance of a greater effect of amphetamine upon cage crossings in Figure 2 than in Figure 1 is largely a result of the difference in ordinate scales, amphetamine-treated 9-day-olds in the present experiment did, in fact, make slightly more

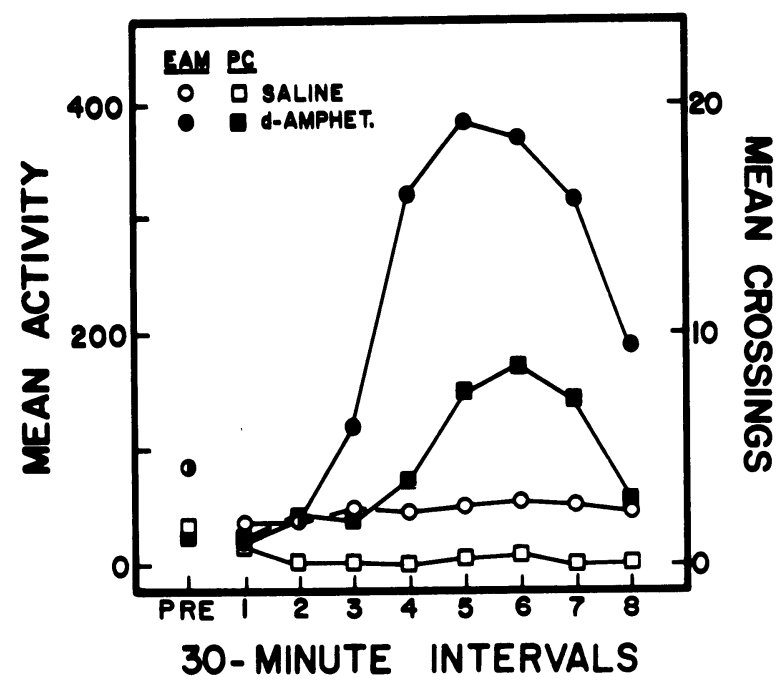

Figure 2. Mean EAM activity (left scale) and cage crossings (right scale) for 9-day-old mice treated with d-amphetamine or saline. 
crossings than did those of Experiment 1. In order to determine if the acrylic cage floor (as opposed to the grid floor used in Experiment 1) could account for this difference, the activity data from 9-day-olds of Experiments 1 and 2 were compared in a four-way analysis of variance, with drug, floor type, sex, and 30-min intervals as factors. The main effect of floor type and all interactions containing the floor-type factor were nonsignificant (all Fs $\leqslant 3.2$ ).

\section{EXPERIMENT 3}

The fact that EAM activity was potentiated more by amphetamine than photocell cage crossings suggested that the EAM activity measure was more sensitive to those activity changes induced by amphetamine at 9 days of age. Therefore, it was expected that measurement of activity by the EAM apparatus would provide a more powerful test for the presence of amphetamine-induced activity increases in younger mice.

\section{Method}

Animals. The animals were $96 \mathrm{~S}-\mathrm{W}$ mice born and reared under the conditions outlined in Experiment 1.

Apparatus. Mice were tested in an opaque-walled acrylic open field $(23.5 \times 23.5 \times 15 \mathrm{~cm})$ that was placed on the sensing surface of the Stoelting EAM. The EAM power supply was set at .8 mA, and normal threshold reset time was selected. The open field was housed in the sound-attenuated chamber used in Experiment 2. Apparatus located outside the chamber recorded total activity within 30-min intervals.

Procedure. Separate groups of eight male and eight female mice were tested at 5,7 , or 9 days of age following injection of saline or d-amphetamine. The procedure was identical to that outlined for 9-, 11-, and 13-day-olds in Experiment 1, with the exception that the EAM recorded activity in the open field.

\section{Results}

Body weights of mice assigned to the various age, sex, and drug groups were subjected to a three-way analysis of variance. No main effects of sex or drug were obtained in this analysis (Fs $<2.2$ ), indicating that there were no overall differences in body weights between sexes or between the mice assigned to amphetamine or saline groups. However, the slightly lower body weights of the 9-day-old amphetamine group, as compared with those of the 9-day-old saline group, contributed to a significant drug $\times$ age $[F(2,84)=4.1, p<.025]$ interaction.

Mean pre- and postinjection activity for 5-, 7-, and 9-day-olds following saline or amphetamine treatment are shown in Figure 3 as a function of 30-min intervals. A three-way analysis of variance conducted on preinjection activity yielded no effects that would indicate an unsuccessful preinjection matching procedure, age being the only significant effect obtained $[\mathrm{F}(2,84)=7.2$, $\mathrm{p}<.005$, all other $\mathrm{Fs}<1.0]$. Postinjection activity was subjected to a four-way analysis of variance, with age, sex, drug, and 30-min

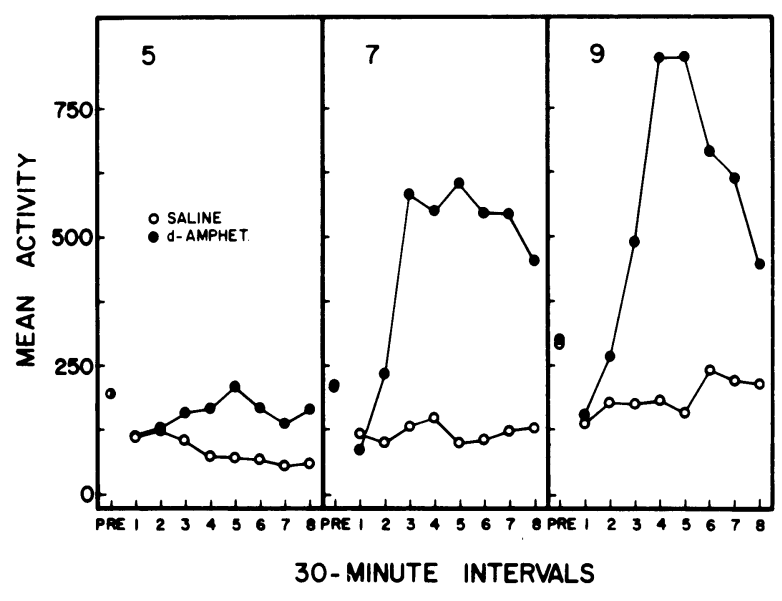

Figure 3. Mean pre- and postinjection EAM activity as a function of age, drug group, and 30 -min intervals.

intervals as factors. A main effect of drug $[F(1,84)=$ $50.6, \mathrm{p}<.0005$ ] reflected the greater overall activity of the amphetamine groups, as compared with that of the saline groups, at all ages tested. However, individual comparisons (after Winer, 1971) conducted within the drug $x$ age interaction indicated that only the 7- and 9-day-old amphetamine groups reliably differed from their like-aged saline groups (Fs $\geqslant$ 29.0, ps $<.005$ ).

The temporal pattern of activity for amphetaminetreated mice was similar at all ages, with the greatest potentiation of activity occurring approximately $2 \mathrm{~h}$ after injection. However, the magnitude of amphetamine-induced activity increased substantially with age, resulting in significant two- and three-way interactions of drug, age, and intervals (all Fs $>2.4$, all ps $<.01$ ).

In order to determine if the greater variability of the 7- and 9-day-old data $\left[\mathrm{F}_{\max }(2,32)>5.3\right.$, ps $\left.<.01\right]$ had obscured an otherwise reliable effect of amphetamine upon the activity of 5-day-olds, the data from the 5-day-olds were subjected to a separate three-way analysis of variance. That analysis indicated the presence of a reliable effect of amphetamine injections at 5 days of age $[F(1,28)=7.5, p<$ $.025]$. Separate analyses of variance conducted at 7 and 9 days of age did not change previous decisions based upon drug group comparisons within the overall analysis.

\section{DISCUSSSION}

The present results are in general agreement with findings indicating that locomotor stimulant effects of d-amphetamine in rats can be obtained soon after birth and considerably earlier in ontogeny than locomotor effects of drugs affecting cholinergic and some serotonergic systems (Campbell et al., 1969; Mabry \& Campbell, 1974). Activity increases in response to 
amphetamine were detected as early as 5 days of age in the present study, while evidence suggests that locomotor responses to the serotonin antagonist methysergide and the anticholinergic scopolamine emerge later during ontogeny in S-W mice. Increased photocell cage crossings following methysergide are not evident until the mice are 13 days old (Porada, 1975), while adult-like cage-crossing responses to scopolamine are not obtained until the mice are approximately 19 days old (Ray \& Nagy, 1978). Although the effects of methysergide upon EAM activity had not been investigated, an unpublished study from this laboratory has indicated that agerelated changes in response to scopolamine are nearly identical for EAM activity and photocell cage crossings.

While it would appear likely that CA systems begin to function prior to cholinergic and serotonergic systems in mice, the present studies indicate only that CA activity can be stimulated by d-amphetamine at early ages. This would imply that functional CAcontaining neurons are present very early in development, although studies of the effects of postsynaptic CA blockade in young mice would be necessary to determine those ages when CA neurons actually participate in norma' activity.

In agreement with reports on the rat, infant mice in the present studies showed a longer period of hyperactivity and a later peak response than those reported for adult mice following equivalent systemic amphetamine treatment. The full time course of amphetamine-induced hyperactivity can be observed within $1 \mathrm{~h}$ following injection in adult S-W mice (Forster, Nagy, \& Murphy, 1981), while the present studies indicated that between the ages of 5 and 13 days hyperactivity occurs over a period of 1 to $4 \mathrm{~h}$ following amphetamine injections. The age-related differences in the temporal characteristics of the amphetamine effect may be, in part, a consequence of neurological changes in the developing CA system (see Bauer, 1980), although it is likely that other factors account for at least some of these temporal effects. Lytle and Meyer (1978) observed that agerelated differences in the temporal pattern of amphetamine-induced hyperactivity of rats were positively correlated with age-related differences in the rates of d-amphetamine's accumulation in and disappearance from the brain. These authors suggested that the temporally protracted amphetamine-induced activity that is observed in young rats might be a consequence of slower metabolism of amphetamine by young rats than by older rats.

While the present studies did not directly address the question of whether amphetamine-induced behaviors differ qualitatively as a function of age, such a hypothesis could account for the age-related changes in quantity of amphetamine-induced loco- motor activity as recorded in our automated apparatus. In the present study, it was found that amphetamine induced very few cage crossings in 9day-old mice but greatly potentiated crossings of 11 and 13-day-olds. The fact that amphetamine effects at 9 days of age were most evident in terms of the more general EAM activity measure may reflect that some activity of 9-day-olds is of a more restricted nature than is activity of 11- and 13-day-olds. For example, Barrett, Caza, Spear, and Spear (1982) have recently reported that $4 \mathrm{mg} / \mathrm{kg}$ dl-amphetamine induces wall climbing (alternate forepaw treading against a wall) in 10-day-old, but not in 15-day-old, rats. The EAM apparatus would be expected to be sensitive to wall climbing as well as to other restricted locomotor movements, whereas the photocell-cage measure is specifically designed for measuring net forward progression. It is clear, however, that descriptive studies will be necessary to determine if mice and rats show a qualitatively similar locomotor response to amphetamine at young ages.

\section{REFERENCES}

Bauer, R. H. The effects of $1-$, d-, and parahydroxy-amphetamine on locomotor activity and wall climbing in rats of different ages. Pharmacology, Biochemistry and Behavior, 1980, 13, 155-165.

Barrett, B. A., Caza, P., Spear, N. E., \& Spear, L. P. Wall climbing, odors from the home nest and catecholaminergic activity in rat pups. Physiology \& Behavior, 1982, 29, 501-507.

Campbell, B. A., Lytle, L. D., \& Fibiger, H. C. Ontogeny of adrenergic arousal and cholinergic inhibitory mechanisms in the rat. Science, 1969, 166, 635-637.

Campbell, B. A., \& Mabry, P. D. The role of catecholamines in behavioral arousal during ontogeny. Psychopharmacology, 1973, 31, 371-379.

Forster, M. J., Nagy, Z. M., \& Murphy, J. M. Potentiation of amphetamine-induced hyperactivity in the adult mouse following neonatal thyroxine administration. Bulletin of the Psychonomic Society, 1981, 18, 337-339.

Lanier, L. P., Dunn, A. J., \& Van Hartesveldt, C. Development of neurotransmitters and their function in brain. In $S$. Ehrenpreis \& I. J. Kopin (Eds.), Reviews of neuroscience (Vol. 2). New York: Raven Press, 1976.

Lytle, L. D., \& MEYer, E. JR. Developmental neurochemical and behavioral effects of drugs. In A. Vernadakis, E. Giacobini, \& G. Filogamo (Eds.), Maturation of neurotransmission. Basel: Karger, 1978.

Mabry, P. D., \& Campbell, B. A. Ontogeny of serotonergic inhibition of behavioral arousal in the rat. Journal of Comparative and Physiological Psychology, 1974, 86, 193-201.

PoradA, K. J. Development of cholinergic and serotonergic inhibitory capacities in undernourished mice. Unpublished MA thesis, Bowling Green State University, 1975.

RAY, D., \& NAGY, Z. M. Emerging cholinergic mechanisms and ontogeny of response inhibition in the mouse. Journal of Comparative and Physiological Psychology, 1978, 92, 335-349.

Sobrian, S. K., Weltman, M., \& Pappas, B. A. Neonatal locomotor and long-term behavioral effects of d-amphetamine in the rat. Developmental Psychobiology, 1975, 8, 241-250.

WINER, B. J. Statistical principles in experimental design (2nd ed.). New York: McGraw-Hill, 1971.

(Manuscript received February 8, 1982; revision accepted for publication October 23, 1983.) 